\title{
Pharmacy Student Facilitation of Reporting of Adverse Drug Reactions in a Hospital
}

\author{
Jason Wentzell, Tiffany Nguyen, Stephanie Bui, and Erika MacDonald
}

\begin{abstract}
Background: Health Canada relies on health professionals to voluntarily report adverse reactions to the Canada Vigilance Program. Current rates of reporting adverse drug reactions (ADRs) are inadequate to detect important safety issues.
\end{abstract}

Objective: To assess the impact of pharmacy student facilitation of ADR reporting by pharmacists at a tertiary care teaching hospital in Canada.

Methods: The intervention of interest, implemented at one campus of the hospital, was facilitation of ADR reporting by pharmacy students. The students received training on how to submit ADR reports and presented information sessions on the topic to hospital pharmacists; the pharmacists were then encouraged to report ADRs to a designated student for formal reporting. Frequency of reporting by pharmacists at the intervention campus was compared with reporting at a control campus of the same hospital. Data were collected prospectively over a 6-month pilot period, starting in April 2015.

Results: During the pilot period, 27 ADR reports were submitted at the intervention campus, and 3 reports at the control campus. All student participants strongly agreed that they would recommend that responsibility for submitting ADR reports to the Canada Vigilance Program remain with pharmacy students during future rotations.

Conclusions: Availability of a pharmacy student to facilitate reporting of ADRs may increase the frequency of ADR reporting and could alleviate pharmacist workload; this activity is also a potentially valuable learning experience for students.

Keywords: adverse drug reaction, adverse drug reaction reporting, hospital pharmacist, pharmacy student

Can J Hosp Pharm. 2017;70(4):276-80

\section{RÉSUMÉ}

Contexte : Santé Canada compte sur les professionnels de la santé pour signaler sur une base volontaire les réactions indésirables au programme Canada Vigilance. Les taux actuels de déclaration des réactions indésirables aux médicaments (RIM) ne permettent pas de repérer les problèmes de sécurité importants.

Objectif : Évaluer l'effet d'une intervention permettant aux étudiants en pharmacie de faciliter la déclaration des RIM par les pharmaciens dans un hôpital universitaire de soins tertiaires au Canada.

Méthodes : L'intervention en question, mise en place dans l'un des établissements de l'hôpital, se résumait à permettre aux étudiants en pharmacie de faciliter la déclaration de RIM. Les étudiants étaient formés pour soumettre des déclarations de RIM et ont présenté des séances d'information sur le sujet aux pharmaciens d'hôpitaux; ces derniers étaient ensuite encouragés à signaler les RIM à un étudiant désigné qui procédait alors à une déclaration formelle. La fréquence de déclaration par les pharmaciens à l'établissement où l'intervention était mise en place a été comparée à celle d'un établissement témoin du même hôpital. Les données ont été recueillies de façon prospective sur une période de six mois pour l'étude pilote qui a commencé en avril 2015.

Résultats : Pendant l'étude pilote, on a procédé à 27 déclarations de RIM à l'établissement où a eu place l'intervention alors que, dans l'établissement témoin, on en a signalé que trois. L'ensemble des étudiants ayant participé étaient tout à fait d'accord pour que la responsabilité de produire des déclarations de RIM au programme Canada Vigilance demeure une tâche pour les étudiants en pharmacie au cours de stages futurs.

Conclusions : La mise à contribution d'un étudiant en pharmacie pourrait accroître la fréquence de déclaration des RIM et pourrait réduire la charge de travail du pharmacien. De plus, cette tâche peut représenter une expérience d'apprentissage précieuse pour les étudiants.

Mots clés : réaction indésirable aux médicaments, déclaration des réactions indésirables aux médicaments, pharmacien d'hôpital, étudiant en pharmacie 


\section{INTRODUCTION}

$\mathrm{H}$ ealth Canada relies on health professionals to voluntarily report adverse reactions to the Canada Vigilance Program. Current rates of reporting adverse drug reactions (ADRs) are inadequate to detect important safety issues.

Health Canada defines adverse reactions as "undesirable effects from health products". ${ }^{1}$ Such effects include any undesirable patient effect suspected to be associated with health product use. Unintended effect, health product abuse, overdose, interaction (including drug-drug and drug-food interactions) and unusual lack of therapeutic efficacy are all considered to be reportable adverse reactions.

Any suspected adverse reaction should be reported to Canada's postmarket surveillance program. ${ }^{2}$ It has been estimated that only $1 \%$ to $10 \%$ of reportable ADRs are reported to voluntary ADR programs. ${ }^{3}$ A study of drugs withdrawn from the Canadian market over the period 1990 to 2009 revealed a median time from market authorization to market withdrawal of 1271 days; in other words, drugs eventually deemed inappropriate for sale in Canada were available for use for nearly 4 years before a decision was made to withdraw market authorization. ${ }^{4} \mathrm{~A}$ well-known example of the inadequacy of the current system of pharmacovigilance in Canada and the United States relates to rofecoxib. After 5 years of sale on the Canadian and US markets, this drug was estimated to have resulted in 88000 to 140000 excess cases of serious coronary heart disease in the United States alone, before being withdrawn in $2004 .^{5}$

Health Canada has recognized the need to improve its current system of postmarket surveillance of medications and is moving toward a "lifecycle approach" to pharmacovigilance of health products, whereby "For example, the benefit-risk of the product could be re-evaluated following market authorization when a new safety signal arises, after which the terms and conditions could be changed and the market authorization amended, suspended or revoked by the Minister." ${ }^{3}$ Part of this plan involves eventual implementation of mandatory reporting of ADRs by hospitals. ${ }^{7,8}$ In theory, this could be an important part of the solution to the current inadequacy of the system of postmarket surveillance. However, reporting rates have been shown to be low, even in countries, such as New Zealand, where reporting of ADRs by health professionals is mandatory, ${ }^{9}$ and enforcing such a requirement would be challenging. ${ }^{7}$

The objective of this study was to assess the impact of pharmacy student facilitation of ADR reporting by pharmacists at a large tertiary care teaching hospital in Ontario.

\section{METHODS}

Ethics approval was obtained from the Ottawa Health Science Network Research Ethics Board. Informed consent was obtained from pharmacists and pharmacy students who participated in the surveys.
The study took place at 2 campuses of a tertiary care teaching centre in Ottawa, Ontario. The intervention of interest was pharmacy student facilitation of ADR reporting. This activity was implemented over an initial 6-month pilot period (starting in April 2015) at one of the institution's campuses, designated the "intervention campus", before expansion to all campuses. At another campus (hereafter referred to as the "control campus"), there was no change to the process of ADR reporting. The 2 campuses were similar with respect to the number and qualifications of pharmacists and the number of pharmacy students on rotation. The diversity of clinical specialties was also similar for the 2 campuses; however, only the intervention campus had admitting oncology and malignant hematology services. Most of the pharmacists working at this institution were employed full-time, with clinical assignment to a specific ward or service. ADR reports submitted by managers, drug information pharmacists, and pharmacy residents were not included in this study.

Before initiation of the intervention, pharmacists at both the intervention and the control campuses were invited to attend an educational session presented by a pharmacy student (S.B.), who described the importance of ADR reporting, which ADRs to report, and how to report them. The student had completed the educational modules available on Health Canada's website for "Health Professional Reporting of Adverse (Drug) Reactions" (www.hc-sc.gc.ca/dhp-mps/medeff/centre-learn-appren/hcpps_ar-ei_module-eng.php) and used this content in generating the formal educational presentation for participating pharmacists. All pharmacists at the intervention campus were additionally made aware (at this session, by e-mail, through verbal reminders, and at regular biweekly staff meetings) that if a patient experienced an ADR that the pharmacist believed should be reported to Health Canada, the pharmacist could contact a designated pharmacy student, referred to hereafter as the "ADR student". Students on rotation in their third or final year of an entry-level PharmD program were given the opportunity to act as the ADR student.

At the beginning of an ADR student's rotation, the student received training from a pharmacist or the current ADR student on how to report ADRs; the incoming ADR student also completed a Canada Vigilance Program online training module. At the intervention campus, pharmacists wishing to report an ADR were instructed to contact the ADR student through an internal e-mail address. Upon receipt of an e-mail message from a pharmacist about a potential ADR, the ADR student gathered the necessary information as thoroughly as possible from the patient's health record for reporting the ADR to the Canada Vigilance Program on the pharmacist's behalf. The ADR student liaised with the pharmacist who initially identified the ADR, as needed, to obtain additional information or clarification. The pharmacist who initially identified the ADR was given the opportunity to review the ADR report before it was submitted. Additionally, the ADR student presented a summary of ADRs reported by the institution's pharmacists at monthly staff meetings at the intervention campus. At any given time, 1 or 2 pharmacy 
students in their final year on clinical rotation were designated as ADR students. At the control campus, pharmacists were encouraged to submit ADR reports themselves, as per existing practice.

The outcomes of interest were the change in frequency of ADR reporting before and after facilitation of reporting by the ADR student was implemented, the mean number of ADR reports submitted per pharmacist, the total number of ADR reports submitted, the characteristics of ADR reports submitted by the ADR student, pharmacy students' satisfaction with incorporation of $\mathrm{ADR}$ reporting into their hospital rotations, and pharmacists' satisfaction with facilitation of ADR reporting by pharmacy students.

A survey was sent to all pharmacists at both the intervention and control campuses at the time that the ADR student became available and again at the end of the 6-month pilot period. This survey contained questions about current reporting practices, perceived barriers to ADR reporting, and, for the intervention campus, pharmacists' satisfaction with ADR reporting by students at the end of the 6-month pilot period. Survey responses from all pharmacists who consented to participate were included.

For each ADR, data extracted from the ADR reports were drug and drug class (according to the AHFS Clinical Drug Information classification system of the American Society of HealthSystem Pharmacists), severity of the reaction (severe or not severe), whether the reaction was expected or unexpected (based on whether or not it is listed in the Canadian product monograph), the ADR report identification number provided by Health Canada, whether or not the drug was a newly marketed medication ( $<5$ years on the market), and the initials of the pharmacist reporting the ADR. The severity of all reported reactions was assessed against Health Canada's definition, ${ }^{1}$ initially by the ADR student and then, for confirmation, by a pharmacist.

The ADR students were also asked to participate in a survey at the end of their rotation to determine their satisfaction with the process of facilitating ADR reporting. Survey responses from all students who consented to participate were included.

\section{Table 1. Characteristics of Adverse Drug Reaction Reports Submitted at the Intervention Site}

\begin{tabular}{lrr} 
Characteristic & $\begin{array}{c}\text { No. (\%) of Reports } \\
(\boldsymbol{n}=\mathbf{2 7})\end{array}$ \\
\hline Drug class* & 5 & $(19)$ \\
Antibiotic & 6 & $(22)$ \\
Antineoplastic & 3 & $(11)$ \\
Antiviral & 3 & $(11)$ \\
Antihyperglycemic & 2 & $(7)$ \\
Heavy metal antagonist & 2 & $(7)$ \\
Antifungal & 6 & $(22)$ \\
Other & 22 & $(81)$ \\
Severe reaction & 4 & $(15)$ \\
Unexpected reaction & 9 & $(33)$ \\
Newly marketed drug (within past 5 years) & 23 & $(85)$ \\
At least one of severe reaction, unexpected & & \\
reaction, or newly marketed drug & &
\end{tabular}

\section{Statistical Analysis}

The original intention was to evaluate the change in reporting frequency at each campus. However, data on reporting frequency before the intervention were found to be unreliable and therefore were not used: the frequency of reporting according to survey responses was very different from the number of reports actually collected, and survey respondents were not likely representative of all pharmacists. Therefore, the actual reporting frequency after the ADR student became available was compared between the control and intervention campuses using the Wilcoxon rank sum test for nonparametric data.

\section{RESULTS}

\section{Quantity and Characteristics of ADR Reports Submitted}

Twenty-seven ADR reports were submitted by a total of 4 ADR students at the intervention campus over the 6-month study period, and 3 reports were submitted by pharmacists at the control campus. As noted above, data for the period before implementation of reporting by ADR students were found to be unreliable: the baseline survey response rate was lower than anticipated (20 [45\%] of the 44 pharmacists surveyed), and respondents' ADR reporting frequency according to their survey responses differed substantially from the number of reports collected by the coordinator and/or manager during the year before implementation of the ADR student process.

Because the number of reports collected in the 6 months before implementation of the intervention was very low and did not differ substantially by campus ( 2 reports collected at the intervention campus and 0 reports collected at the control campus), it was decided to compare the frequency of ADR reporting between the 2 campuses during the 6-month pilot implementation period, instead of comparing the change in reporting frequency between the 2 campuses. In this comparison, the difference in number of ADRs reported (27 versus 3 ) was not statistically significant $(p=0.10)$. The data were highly skewed because of the large difference in reporting frequency by a small number of pharmacists, with a median of 0 reports per pharmacist at both the intervention and control campuses.

The number of pharmacists submitting at least $1 \mathrm{ADR}$ was higher at the intervention campus than at the control campus (37.5\% [9/24] versus $10 \%$ [2/20]; $p=0.044)$. The 2 pharmacists reporting most frequently at the intervention campus accounted for 13 of the 27 ADRs reported. All 27 ADR reports submitted at the intervention campus were completed with the help of the ADR student. Three of the reports involved more than one suspected drug. Health Canada's adverse reaction reporting guide for health professionals ${ }^{6}$ notes that the department is particularly interested in reports of adverse reactions that are severe, unexpected, or related to newly marketed drugs; 23 (85\%) of the $27 \mathrm{ADR}$ reports submitted at the intervention campus met at least 
one of these criteria. Other characteristics of the submitted ADR reports are summarized in Table 1.

\section{Pharmacy Student Survey}

Participating students $(n=4)$ mostly served as the ADR student for a period of 5 to 8 weeks, depending on their rotation length. Completion of the satisfaction survey was voluntary. All 3 of the students who responded to the survey strongly agreed that participation in this pilot study promoted independence and a sense of responsibility and improved intraprofessional communication with their pharmacist colleagues; they also reported that they felt more comfortable with the ADR reporting process and would be more likely to report ADRs to Health Canada in the future. All of the student respondents also strongly agreed that they would recommend that responsibility for submitting ADR reports to the Canada Vigilance Program remain with pharmacy students during future rotations. Students reported spending about 30 to 120 minutes per report, and an average of 0 to 60 minutes per day on related activities. The 2 students who responded to the survey were divided as to whether the activities associated with this pilot program did not interfere with other rotation activities, either disagreeing $(n=1)$ or strongly agreeing $(n=1)$.

\section{Pharmacist Survey}

A total of 20 pharmacists completed some or all of the baseline survey, 8 at the control campus and 12 at the intervention campus. The baseline demographic characteristics, responses to survey questions, and identified barriers to ADR reporting before the intervention are detailed in Appendix 1.* A total of 16 pharmacists completed some or all of the 6-month follow-up survey, 6 at the control campus and 10 at the intervention campus. Results from the follow-up surveys, including barriers to ADR reporting, are provided in Appendix 2. As part of this follow-up survey, pharmacists were asked to detail their satisfaction with various components of the ADR program that had been implemented at their respective campuses (Appendix 3). Most of the pharmacists at the intervention campus who responded to this survey agreed or strongly agreed that they were more likely to report ADRs after the ADR student became available (4/5 [20\%]) and that they would like to see the ADR student role continued beyond the pilot implementation period (4/5 [20\%]). Most of the responding pharmacists agreed or strongly agreed that they were confident in the accuracy of the information reported by the ADR student (3/5 [60\%]).

\section{DISCUSSION}

The availability of a designated pharmacy or PharmD student responsible for reporting ADRs identified by pharmacists was associated with increases in the number of ADRs reported

\footnotetext{
*All appendices for this article are available from https://www.cjhponline.ca/index.php/cjhp/issue/view/122/showToc
}

(although not statistically significant) and the number of pharmacists reporting ADRs at the study institution. Participating pharmacists found that this system of ADR reporting was practical, did not interfere significantly with their own daily activities, and reduced the number of perceived barriers to ADR reporting. In addition, student respondents felt that they gained insight into the ADR reporting process and strongly agreed that the role should be incorporated into subsequent student rotations at the study institution. This is an example of an initiative conducted at a tertiary care institution that aimed to incorporate opportunities for inter- and intra-professional collaboration for participating pharmacy students within the framework of a clinical rotation and that contributed to real-time patient care.

This intervention was timely, in that the Canadian government recently passed new legislation aimed at increasing the safety of medications available to Canadians. ${ }^{8}$ Although specific regulations have not been detailed, mandatory reporting of ADRs by hospitals is on the horizon. In this study, implementation of an ADR reporting process managed by pharmacy students led to increased reporting of ADRs and a decrease in perceived barriers to ADR reporting, with minimal change to pharmacists' daily practice. In addition, the students involved became familiar with the procedure and importance of ADR reporting and may be more likely to continue this practice in the future.

One potential barrier to the sustainability of this system of ADR reporting, which was identified during the 6-month pilot implementation period, was the requirement to train the ADR student in ADR-related duties. During the pilot period, a pharmacist was responsible for training each new ADR student. In the future, development of an electronic training module for incoming students could help to alleviate this burden. In addition, student availability and accessibility varied at the practice sites; currently, there are periods of several weeks each year when no pharmacy students are on rotation at each campus. This limitation could be overcome by scheduling student rotations to ensure continuous coverage whenever feasible and by asking that incoming ADR students complete the reporting process for any ADRs left over from the period preceding their arrival. Given that ADR students can be expected to spend up to 60 minutes per day on $\mathrm{ADR}$ reporting activities, this should be considered in the context of the student's other rotation objectives and responsibilities.

This study had several limitations. The intervention and control campuses differed in several respects, apart from the intervention of interest. For example, only the intervention campus had admitting oncology and malignant hematology services, where ADRs could be expected to occur more frequently. Although pharmacists at both campuses are asked to notify a coordinator or manager when they submit ADRs to the Canada Vigilance Program, it is possible that some ADRs submitted during the 6 months before and after the pilot implementation period were not accounted for by this notification process. In fact, it is quite likely that ADRs reported in the 6 months before the implementation period were not accounted for, because the self- 
This single copy is for your personal, non-commercial use only.

For permission to reprint multiple copies or to order presentation-ready copies for distribution, contact CJHP at publications@cshp.ca

reported number of ADRs differed substantially from the number collected by the coordinators and managers in the same period (e.g., for the intervention campus, 2 collected by coordinators/ managers versus 12 self-reported in the pharmacist survey), and this discrepancy is likely inflated by recall bias. In addition, survey response rates were quite low (45\% overall). Participants were recruited for participation in the survey via e-mail over a period of 7 to 10 days, which may not have been enough time to optimize opportunity for participation. It is possible that pharmacists responding to the survey differed from nonrespondents with respect to ADR reporting practices and opinions. Additionally, those pharmacists who reported most frequently over the 6-month period and the pharmacy students on rotation at the study site may not be representative of the broader population of pharmacists and pharmacy students, which may limit applicability of this study to other sites. The 6-month pilot implementation period was also of relatively short duration.

We intend to maintain and build on this system of ADR reporting, through expansion to additional sites at the study institution and involvement of health professionals outside of pharmacy. In addition to improving adherence to ADR reporting, future research should focus on the characterization of ADRs and should optimize the identification and selection of reportable ADRs, to provide practical guidance to other health care practitioners. Successful implementation of student facilitation of ADR reporting at other institutions could increase the frequency of ADR reporting across Canada and improve the safety of medications currently available to Canadians. Future research involving other health professionals, community pharmacies, and family health teams could also be pursued. Incorporation of ADR reporting into the curricula of pharmacy programs could help to promote a culture of ADR reporting among pharmacists and students, as well as helping to fill an identified need for qualified researchers in the area of postmarket surveillance in Canada. ${ }^{10}$

\section{CONCLUSION}

Availability of a pharmacy student to facilitate reporting of ADRs may increase the frequency of ADR reporting, is a potentially valuable learning experience for students, and could alleviate pharmacist workload.

\section{References}

1. Adverse reaction and medical device problem reporting. Ottawa $(\mathrm{ON})$ : Health Canada; 2016 [cited 2017 Aug 15]. Available from: https:// www.canada.ca/en/health-canada/services/drugs-health-products/medeffectcanada/adverse-reaction-reporting.html
2. Canada Vigilance Program. Ottawa (ON): Health Canada; 2016 [cited 2017 Aug 15]. Available from: https://www.canada.ca/en/health-canada/services/ drugs-health-products/medeffect-canada/canada-vigilance-program.html

3. Hazell L, Shakir SAW. Under-reporting of adverse drug reactions: a systematic review. Drug Saf. 2006;29(5):385-96.

4. Lexchin J. How safe are new drugs? Market withdrawal of drugs approved in Canada between 1990 and 2009. Open Med. 2014;8(1):e14-9.

5. Graham DJ, Campmen D, Hui R, Spence M, Cheetham C, Levy G, et al. Risk of acute myocardial infarction and sudden cardiac death in patients treated with cyclo-oxygenase 2 selective and non-selective non-steroidal anti-inflammatory drugs: nested case-control study. Lancet. 2005;365 (9458):475-81.

6. Health product vigilance framework. Ottawa (ON): Health Canada; 2012 Sep [cited $2014 \mathrm{Jan}$ ]. Available from: https://www.canada.ca/en/healthcanada/services/drugs-health-products/reports-publications/medeffectcanada/health-product-vigilance-framework-health-canada-2012.html

7. Smith J, chair. Post-market surveillance of pharmaceuticals: report of the Standing Committee on Health. 39th Parliament, 2nd Session. Ottawa (ON): House of Commons; 2008 Jun [cited 2014 Jan]. Available from: www. ourcommons.ca/Content/Committee/392/HESA/Reports/RP3598191/ hesarp07/hesarp07-e.pdf

8. Protecting Canadians from Unsafe Drugs Act (Vanessa’s Law), S.C. 2014, c. 24.

9. Wiktorowicz ME, Lexchin J, Moscou K, Silversides A, Eggertson L. Keeping an eye on prescription drugs, keeping Canadians safe: active monitoring systems for drug safety and effectiveness in Canada and internationally. A commissioned discussion paper. Toronto $(\mathrm{ON})$ : Health Council of Canada; 2010. Available from: http://publications.gc.ca/collections/collection_2011/ ccs-hcc/H174-21-2010-eng.pdf

10. Wiens MO, Soon JA, MacLeod SM, Sharma S, Patel A. Post-market drug evaluation research training capacity in Canada: an environmental scan of Canadian educational institutions. J Popul Ther Clin Pharmacol. 2014; 21(3):e370-8

Jason Wentzell, BScPharm, ACPR, BCOP, is a Pharmacist with The Ottawa Hospital, General Campus, Ottawa, Ontario.

Tiffany Nguyen, BScPharm, ACPR, BCOP, is a Pharmacist with The Ottawa Hospital, General Campus, Ottawa, Ontario.

Stephanie Bui, BSc, PharmD, was, at the time of this study, a PharmD student in the School of Pharmacy, University of Waterloo, Kitchener, Ontario.

Erika MacDonald, BSCPharm, ACPR, MSC, is a Pharmacist with The Ottawa Hospital, Civic Campus, Ottawa, Ontario.

Competing interests: None declared.

Address correspondence to:

Erika MacDonald

The Ottawa Hospital, Civic Campus

1053 Carling Avenue

Ottawa ON K1Y 4E9

e-mail: erimacdonald@toh.ca

Funding: None received. 